International Journal of Environmental Research and

\title{
Addendum: Shiue, I.; et al. 2014 Future Earth Young Scientists Conference on Integrated Science and Knowledge Co-Production for Ecosystems and Human Well-Being. Int. J. Environ. Res. Public Health 2014, 11, 11553-11558
}

Ivy Shiue 1,*, Leah Samberg ${ }^{2}$, Benard Kulohoma ${ }^{3,4}$, Diana Dogaru ${ }^{5}$, Carina Wyborn 2,†, Perrine Hamel ${ }^{6}$, Peter Søgaard Jørgensen ${ }^{7,8}$, Paul Lussier ${ }^{9}$, Bharath Sundaram ${ }^{10}$, Michelle Lim ${ }^{11}$ and Antonio Tironi ${ }^{12}$

1 School of Energy, Geoscience, Infrastructure and Society, Heriot-Watt University, Riccarton, Edinburgh EH14 4AS, Scotland, UK

2 College of Forestry and Conservation, University of Montana, Missoula, MT 59812, USA; E-Mails: 1samberg@gmail.com (L.S.); cwyborn@wwfint.org (C.W.)

3 International Centre of Insect Physiology and Ecology, Nairobi, Kenya;

E-Mail: bkulohoma@iscb.org

4 Centre for Biotechnology and Bioinformatics, University of Nairobi, Nairobi, Kenya

5 Environment \& GIS Department, Institute of Geography, Romanian Academy, Bucharest 023993, Romania; E-Mail: dianadogaru77@yahoo.com

6 The Natural Capital Project, Woods Institute for the Environment, Stanford University, Stanford, CA 94305, USA; E-Mail: perrine.hamel@ stanford.edu

7 Center for Macroecology, Evolution and Climate, Department of Biology, University of Copenhagen, Copenhagen 2100, Denmark; E-Mail: psjorgensen@bio.ku.dk

8 International Network of Next-Generation Ecologists, Universitetsparken 15, Building 3, Copenhagen 2100, Denmark

$9 \quad$ Yale Climate \& Energy Institute, Yale University, New Haven, CT 06520, USA; E-Mail: paul.lussier@yale.edu

10 Azim Premji University, Bangalore 560100, India; E-Mail: b.sundaram@apu.edu.in

11 Centre for Water Law, Policy and Science, University of Dundee, Dundee DD1 4HN, UK; E-Mail: m.lim@dundee.ac.uk

12 Fundación CTF, Padre Mariano 391 \#704, Providencia, Santiago, Chile; E-Mail: atironi@ctf.cl

$\dagger$ Current address: Luc Hoffman Institute, WWF International, Avenue du Mont-Blanc, 1196 Gland, Switzerland. 
* Author to whom correspondence should be addressed; E-Mail: I.shiue@ @w.ac.uk;

Tel.: +44-131-451-4655; Fax: +44-131-451-3161.

Received: 5 December 2014 / Accepted: 10 February 2015 / Published: 12 February 2015

The authors would like to add the following affiliation for Peter Søgaard Jørgensen of paper [1]:

8 International Network of Next-Generation Ecologists, Universitetsparken 15, Building 3, Copenhagen 2100, Denmark

The authors apologize for any inconvenience caused to the readers.

\section{Reference}

1. Shiue, I.; Samberg, L.; Kulohoma, B.; Dogaru, D.; Wyborn, C.; Hamel, P.; Jørgensen, P.S.; Lussier, P.; Sundaram, B.; Lim, M.; Tironi, A. 2014 Future Earth Young Scientists Conference on Integrated Science and Knowledge Co-Production for Ecosystems and Human Well-Being. Int. J. Environ. Res. Public Health 2014, 11, 11553-11558.

(C) 2015 by the authors; licensee MDPI, Basel, Switzerland. This article is an open access article distributed under the terms and conditions of the Creative Commons Attribution license (http://creativecommons.org/licenses/by/4.0/). 